\title{
Functional Analysis of RELN S2486G Mutation and its Contribution to Pathogenesis of Ankylosing Spondylitis
}

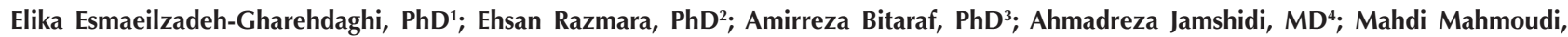
PhD $^{4,5}$; Masoud Garshasbi, PhD $^{1^{*}}$

\author{
${ }^{1}$ Department of Medical Genetics, Faculty of Medical Sciences, Tarbiat Modares University, Tehran, Iran \\ ${ }^{2}$ Australian Regenerative Medicine Institute, Monash University, Clayton, VIC 3800, Australia \\ ${ }^{3}$ Department of Molecular Genetics, Faculty of Biological Sciences, Tarbiat Modares University, Tehran, Iran \\ ${ }^{4}$ Rheumatology Research Center, Tehran University of Medical Sciences, Tehran, Iran \\ Inflammation Research Center, Tehran University of Medical Sciences, Tehran, Iran
}

\begin{abstract}
Background: Ankylosing spondylitis (AS; OMIM:106300) is a common complex inflammatory disease; in a previous study, we introduced a novel mutation in the RELN gene (OMIM: 600514) which was associated with AS. This study is designed to investigate the potential effect of RELN S2486G mutation on reelin secretion; additionally, we objected to evaluate the phospholipase A2 (PLA2G7) gene (OMIM: 601690) expression and platelet-activating factor-acetylhydrolase (PAF-AH) concentration as the downstream gene and the encoded protein

Methods: The impact of the S2486G on reelin protein secretion was investigated in CHO-K1 and HEK-293T cells by constructing wild-type and mutant plasmids. Besides, the possible effect of the mutation on expression and concentration of PLA2G7 and PAF-AH in THP1 cells was assessed by quantitative real-time PCR (qRT-PCR) and enzyme-linked immunosorbent assay (ELISA), respectively. The study was performed at Tarbiat Modares University, Tehran, Iran, from 2016 to 2018.

Results: Our results showed that S2486G not only causes a significant reduction in reelin secretion in both HEK-293T and CHO-K1 cells, but also it leads to a significant reduction in PLA2G7 gene expression $(P$ value $<0.001)$ and protein level of PAF$\mathrm{AH}$ in THP-1 cells $(P$ value $<0.003)$.

Conclusion: The S2486G mutation in RELN can alter inflammatory and, to some extent, osteogenesis pathways mediated by reduced secretion of reelin and also reduced expression of the PLA2G7 gene.

Keywords: Ankylosing spondylitis, Inflammation, Platelet-activating factor acetylhydrolase, PLA2G7 protein, Reelin

Cite this article as: Esmaeilzadeh-Gharehdaghi E, Razmara E, Bitaraf A, Jamshidi A, Mahmoudi M, Garshasbi M. Functional analysis of RELN S2486G mutation and its contribution to pathogenesis of ankylosing spondylitis. Arch Iran Med. 2020;23(10):688-696. doi: 10.34172/aim.2020.87.
\end{abstract}

Received: April 15, 2020, Accepted: July 4, 2020, ePublished: October 1, 2020

\section{Introduction}

Ankylosing spondylitis (AS; OMIM:106300) is a chronic inflammatory disease affecting the skeletal systems, mainly the spine and sacroiliac joints. ${ }^{1}$ The chronic inflammation in bone and cartilage tissues causes irreversible damages and remodels the joints' architecture. ${ }^{2}$ The important manifestations of AS are excessive bone formation localized in sacroiliac joints and expanded chronic inflammation. ${ }^{3}$ Additionally, the precise etiopathogenesis of the disease has not been completely uncovered. ${ }^{4}$

In a previous study, we reported a novel heterozygous mutation in the RELN (OMIM: 600514) gene, c.7456 A $>$ G; p.Ser2486Gly, which was associated with AS revealed by a co-segregation study in a large Iranian family. ${ }^{5}$ The encoded protein, reelin protein, is a large extracellular matrix protein that plays a crucial role in neuronal migration during brain development. ${ }^{6,7}$ Different genetic polymorphisms/variations in the RELN gene have been detected and indicated that they are associated with various disorders such as schizophrenia (OMIM: 181500), autistic spectrum disorders (ASD; OMIM:209850), Alzheimer disease (OMIM: 104300), temporal lobe epilepsy (OMIM: 616436), and abnormal development of the cerebral cortex and hippocampus. ${ }^{8,9}$ Accumulating evidence has shown the fluctuation of reelin concentration in brain autopsies and also in the blood samples derived from patients affected by neuropsychiatric disorders such as schizophrenia, bipolar diseases, and ASD. ${ }^{10-12}$ In a nutshell, although various studies confirm the roles of reelin in neurogenesis, the peripheral roles, e.g. in inflammatory pathways, are still unclear.

In humans, the expression of RELN is detectable in the liver, adrenal pituitary cells, fibroblast-like synovial cells, and also osteocyte cells. ${ }^{13-15}$ On the other hand, the expression of $R E L N$ is in the lowest (or even undetectable) level in blood samples. Abnormal expression of RELN has been detected in different conditions, e.g. various revealed the association between the expression of the RELN gene with rheumatoid arthritis (RA; OMIM: 180300) and also other inflammatory disorders. ${ }^{14,16,17}$ Accumulation of 
reelin has been detected in synovial fluid and also in sera of RA patients. ${ }^{14}$

In 2012, Du et al showed that reelin could promote Pla2g7 gene expression through stimulating very-lowdensity lipoprotein (VLDL) receptors in mice. ${ }^{18}$ This report was the first evidence suggesting the inflammatory role of reelin, although this pathway had not been confirmed in humans. The enzyme of platelet-activating factor-acetylhydrolase (PAF-AH) encoded by the PLA2G7 gene has an anti-inflammatory role that leads to plateletactivating factor (PAF) inactivation. ${ }^{19}$ PAF increases the level of numerous important inflammatory factors, e.g. cyclooxygenase 2 (Cox 2 ) and tumor necrosis factor- $\alpha$ $\left(\right.$ TNF- $\alpha$ ), which play a central role in AS pathogenesis. ${ }^{20}$ Furthermore, PAF functions as the main modulator in cartilage degeneration. ${ }^{21}$

Reelin is composed of eight EGF-like domains separating each constituent tandem repeats ( $R 1$ to $R 8$ ) into two distinct subdomains: A and B (Figure 1A, 1B). ${ }^{22}$ EGF-like domains are typically composed of six conserved cysteine residues that form three intra-domain disulfide bridges. ${ }^{23}$ These domains play an important role in orchestrating protein-protein interactions (Figure 1C), ${ }^{24}$ protein folding, ${ }^{25}$ and receptor binding process. ${ }^{26}$ Substitutions in such domains have potential effects on protein secretion. ${ }^{27}$ The S2486G mutation is located in the receptor-binding site of the reelin ( $6^{\text {th }}$ EGF-like domain). The central fragment of reelin, namely R3 to R6, is not only sufficient for reelin attachment to its specific receptors (VLDLR and ApoER2) but also takes a center stage in activating downstream signals transductions. ${ }^{28}$

Various studies have been performed to cast light on the production and secretion of reelin in cell supernatant and lysates by constructing recombinant reelin plasmids containing receptor binding domains (R5-R6) and C-terminal region (CTR). ${ }^{29}$ Other studies have elucidated that the presence of the CTR of reelin (which is comprised of 32 amino acids) is imperative for efficient downstream signal transduction. ${ }^{29,30}$

In this study, we investigated the potential effect of S2486G mutation on reelin secretion; additionally, we evaluated its effect on the PLA2G7 gene expression and PAF-AH concentration by constructing a subregion of Human RELN containing the R5-R6 domains (wild-type and S2486G mutant) and the CTR. For the first time, we demonstrated that the S2486G mutation not only leads to a reduction of reelin secretion in CHO-K1 and HEK$293 \mathrm{~T}$ cells, but also causes a significant decrease of both the PLA2G7 gene expression and the PAF-AH protein level in THP-1-monocyte/macrophages cells.

\section{Materials and Methods}

Structures and Alignments

The identified mutation, S2486G, is located in the $6^{\text {th }}$ EGF-like domain of the reelin. The protein families and domains were analyzed using ScanProsite ${ }^{31}$ and sequence

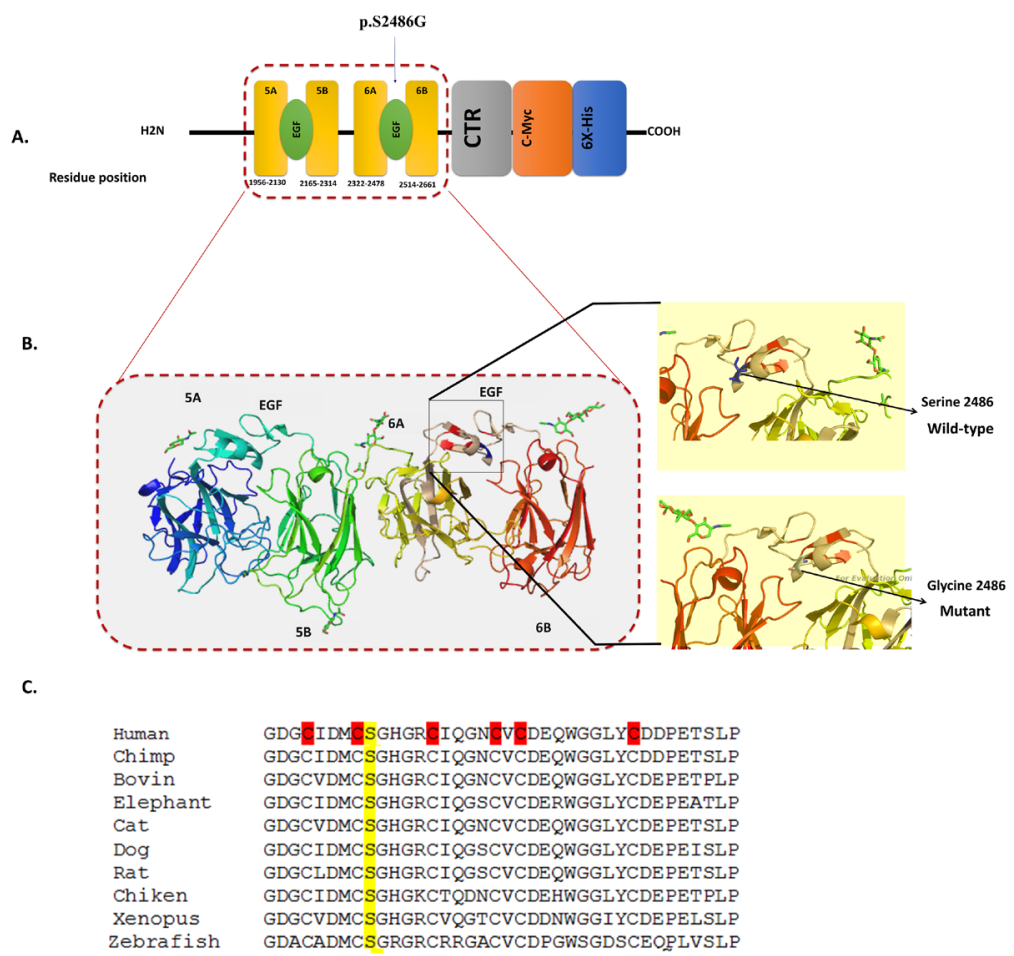

Figure 1. Reelin Structure Which Hemmed in the R5-R6 Region. A) S2486G locates in the EGF-like domain of reelin protein. B) 3D structure was used to check the impact of the S2486G mutation on the stability of the protein structure. According to I-mutant 2.0, the protein stability decreases. Six conserved cysteines of the EGF-like domain are shown in this picture. C) The conservation study was conducted by the ClustalW database. These results show that the mutation is located in a conserved sequence. 
alignments of the human reelin protein were recruited using ClustalW. ${ }^{32}$ The protein structure and mutation impacts on protein flexibility and stability were analyzed by PyMOL ${ }^{33}$ and I-mutant V2.0 $0^{34}$ after the structure was built based on the Phyre $2^{35}$ and SWISS-PROT ${ }^{36}$ in a distinct PDB file. The RAMPAGE online tool was applied to check the detailed residue-by-residue stereochemical quality based on a Ramachandran plot. ${ }^{37}$

\section{Plasmids Constructs}

PVP22/myc-His2 expressing plasmid (Invitrogen, Groningen, The Netherlands) was utilized to construct recombinant plasmids containing R5-R6 domains of reelin carrying on wild-type and S2486G mutant alleles and CTR. The cDNA of K562 cells (ATCC CCL 243) was used to amplify R5-R6 domains (amino acids 19172673) and CTR segment (amino acids 3365-3460) using PfuUltra High-Fidelity DNA Polymerase (Stratagene, La Jolla, CA, USA). The sequence of primers utilized in this study is described in Table S1. The VP22 gene was cut by EcoRI/XbaI restriction enzymes and replaced by CTR (Control plasmid); then, the R5-R6 fragments were added to the constructs employing HindIII/EcoRI restriction enzymes (R5-R6/CWT).

\section{Site-Directed Mutagenesis}

Site-directed mutagenesis using 'Overlap Extension PCR' was applied to introduce the mutation into the R5-R6 fragment. Two mutant primers that had common nucleotides site, around $13 \mathrm{bp}$, were designed for this purpose (Table S1). Then, two fragments were amplified from R5-R6/CWT construct by F-mutant and R-R5/ R6-primers to produce a fragment with 570-bp size. R-mutant and F-R5/R6-primers were utilized to create a fragment of $1714 \mathrm{bp}$. The fragments were isolated from the agarose gel using the High Pure PCR Product Purification Kit (ROCHE, Chicago, USA) and utilized as a template for amplifying a fragment with $2271 \mathrm{bp}$ through external primers (R5/R6-Forward and R5/R6Reverse primers). In the first step, the PCR condition was $30 \mathrm{~s}$ at $95^{\circ} \mathrm{C}, 30$ seconds at $60^{\circ} \mathrm{C}, 30$ seconds at $72^{\circ} \mathrm{C}$, for 15 cycles (without primers) which was followed by 30 seconds at $95^{\circ} \mathrm{C}, 30$ seconds at $52^{\circ} \mathrm{C}, 120$ seconds at $72^{\circ} \mathrm{C}$, for 35 cycles (including primers) and 10 minutes of final extension at $72^{\circ} \mathrm{C}$. The PCR products were cloned followed by digestion by HindIII/EcoRI restriction enzymes. The produced constructs were assessed by Sanger sequencing to verify the introduction of the mutation and also any additional mutations due to possible PCR errors.

\section{Evaluation of Reelin Secretion}

Around $7 \times 10^{5}$ cells from each cell line, i.e. CHO-K1 (ATCC ${ }^{\circledR}$ CCL-61 ${ }^{\mathrm{TM}}$; Rockville, MD, USA) and HEK293T (ATCC ${ }^{\circledR}$ CRL-11268 ${ }^{\mathrm{TM}}$; Temecula, CA, USA), were cultured in RPMI 1640 (Gibco Laboratories, Grand
Island, NY) and DMEM (High Glucose; Invitrogen, Carlsbad, CA, USA) supplemented with 10\% FBS and $1 \mathrm{X}$ penicillin-streptomycin in an incubator with $5 \% \mathrm{CO}_{2}$ and $95 \%$ humidity. By reaching 50\%-60\% confluency in T25 flasks, the cells were transfected with $8 \mu \mathrm{g}$ of each vector containing R5-R6/CWT and R5-R6/CMUT using Lipofectamine $2000^{\circledR}$ reagent Thermo Fisher Scientific, Waltham, MA, USA) according to the manufacturer's instructions. To control transfection efficiency, $\beta$-galactosidase ( $\beta$-Gal) assay was applied by pSV $\beta$ Galactosidase Control Vector (Promega, Madison, WI, USA) and the $\beta$-Gal Staining Set Kit (Roche Diagnostics Corporation, Indianapolis, IN, USA). Cell lysates and supernatants of the cells were utilized for the enzymelinked immunosorbent assay (ELISA) test after 24 and 48 hours of transient transfection.

We used the GST 6XHis tag ELISA kit (ab128573, Abcam, Chicago, USA) and 6XHis tag antibody (ab9108, Abcam, Chicago, USA) with a sensitivity of $0.5 \mathrm{ng} / \mathrm{mL}$ for 6XHis- tagged protein. All the reagents were applied based on standard protocols. Finally, the standard curve was achieved by applying a serial dilution of the standard recombinant GST-6XHistag. This assay was performed in duplicate for both standard and test samples. The supernatants and cell lysates of non-transfected cells were used as negative controls.

\section{PLA2G7 Gene Expression}

The biphasic monocyte/macrophage cells of THP1 (ATCC $^{\circledR}$ TIB-202 ${ }^{\mathrm{TM}}$; Rockville, MD, USA) were cultured in RPMI 1640 supplemented with 10\% FBS, and 1X penicillin-streptomycin in an incubator with $5 \% \mathrm{CO}_{2}$ and $95 \%$ humidity. After 14 days, adherent cells in the macrophage phase were detached using Trypsin/EDTA $0.5 \%$. After washing with PBS, almost $8 \times 10^{5}$ cells were used in five distinct groups. The first plate was utilized as control and another plate was treated with supernatant obtained from the CHO-K1 cells without transfection after $48 \mathrm{~h}$ as 'Control Conditioned Medium (CCM)'. The media derived from transfected CHO-K1 cells with control, R5-R6/CWT, and R5-R6/CMUT plasmids were respectively added to the three remaining plates after normalization.

RNA extraction was achieved using RNX-Plus Solution (CinnaGen, Tehran, Iran) 3 hours after the treatment of the cells. Then, RNA concentration was measured with Nanodrop $2000^{\circledR}$ (Thermo Fisher Scientific, Wilmington, DE, USA) and the synthesis of cDNA was performed using the TAKARA kit (Takara, Otsu, Japan) in $25 \mu \mathrm{L}$ reaction mix. All primers were designed by Primer3.0 online web tool $^{38}$ and qRT-PCR was performed for each sample. Glyceraldehyde 3-phosphate dehydrogenase (GAPDH) was used as the reference gene and consequently, data were analyzed by applying the $\triangle \triangle \mathrm{CT}$ method. ${ }^{39}$ In this study, the Human PLA2G7 ELISA kit (ab235643, Abcam, USA) 
with a sensitivity of $45 \mathrm{pg} / \mathrm{mL}$ was used to evaluate the concentration of the PAF-AH enzyme in the supernatant of THP1 cells $16 \mathrm{~h}$ after treatment with Control, CCM, R5-R6/CWT, and R5-R6/CMUT. ELISA assays were obtained from three independent experiments that were performed in duplicate for all samples and standards. The supernatants and cell lysates of non-transfected cells were used as a negative control for this test.

\section{Statistical Analysis}

Statistical analyses were performed using SPSS v.25.0 (IBM Corp., Armonk, NY, USA) and GraphPad Prism v.7.0 (GraphPad Software Inc, San Diego, CA, USA). Differences between experimental conditions were analyzed by considering $P$ values $<0.05$ as statistically significant.

\section{Results}

In-Silico Prediction

To investigate the impact of the S2486G mutation on reelin secretion, we constructed two expressing plasmids designed as R5-6/C WT and R5-6/C MUT. The S2486G is located in the EGF-like domain of the sixth repeat of reelin protein and located near the second cysteine which is required for forming a disulfide bridge (Figure 1B). In-silico prediction by I-Mutant $2.0^{34}$ showed that the missense S2486G mutation can change protein folding or stability. Additionally, the prediction of O-linked and $\mathrm{N}$-linked glycosylation was achieved based on the average surface accessibility and composition profile of pattern algorithms of GlycoEP. ${ }^{40}$ This result indicates that Serine of 2486 is a potential residue for O-linked glycosylation (residue score: $-1.519, P$ value $<0.05$ ).

We used the RAMPAGE online tool to show the detailed residue-by-residue stereochemical quality by the Ramachandran plot. The modeled structure of reelin R5R6 indicated almost $98 \%$ of residues in the most favored regions, around $2 \%$ of residues in the allowed regions, and only $0.3 \%$ of residues in the outlier regions, which suggested that the modeled structure of reelin R5-R6 was acceptable.

\section{Reelin Secretion}

The reelin secretion in the cell lysates and supernatants, which were collected at different times after transfection from CHO-K1 and HEK-293T cells (Figure 2A, 2B), was evaluated by GST 6XHis tag ELISA kit employing 6XHis tag antibody. Similarly, in-vitro analysis of some identified mutations in the RELN gene related to ASD has demonstrated that those mutations have similar effects on the secretion of the full-length or a subregion of the reelin reading frame. ${ }^{41}$

The signal of 6XHis neither was detected in the conditional medium nor cell lysate from non-transfected CHO-K1 and HEK-293T cells. The cellular concentration of the R5-R6/CWT per $2 \times 10^{6} \mathrm{CHO}-\mathrm{K} 1$ cells was 5.93 $\pm 0.9 \mathrm{ng} \cdot \mathrm{mL}^{-1}$ at 24 hours and $18.33 \pm 2.08 \mathrm{ng} \cdot \mathrm{mL}^{-1}$ at 48 hours and this amount in HEK-293T cells was 4.16 \pm 1.04 ng. $\mathrm{mL}^{-1}$ at 24 hours and $14.4 \pm 1.8 \mathrm{ng} \cdot \mathrm{mL}^{-1}$ at 48 hours. While the intracellular concentration of R5-R6/ CMUT per $2 \times 10^{6} \mathrm{CHO}-\mathrm{K} 1$ cells was $3.3 \pm 0.81 \mathrm{ng} \cdot \mathrm{mL}^{-1}$ at 24 hours and $13.6 \pm 1.52 \mathrm{ng} \cdot \mathrm{mL}^{-1}$ at 48 hours, this amount was $1.58 \pm 0.65 \mathrm{ng} \cdot \mathrm{mL}^{-1}$ at 24 hours and $7.7 \pm$ 2.06 ng. $\mathrm{mL}^{-1}$ at 48 hours in HEK-293T cells (Table 1). These results indicate that the intracellular concentrations of R5-R6/CWT at 24 hours and 48 hours after transient transfection of both cells were significantly more than those of the mutant.

Levels of R5-R6/CWT in the supernatant of CHO-K1 and HEK-293T were $12.53 \pm 2.24 \mathrm{ng} \cdot \mathrm{mL}^{-1}$ at 24 hours, $28.7 \pm 3.2 \mathrm{ng} \cdot \mathrm{mL}^{-1}$ at 48 hours and $7.36 \pm 1.2 \mathrm{ng} \cdot \mathrm{mL}^{-1}$ at 24 hours, and $26.53 \pm 1.6 \mathrm{ng} \cdot \mathrm{mL}^{-1}$ at $48 \mathrm{~h}$ respectively. The supernatant concentration of R5-R6/CMUT in CHO-K1 was $6.83 \pm 0.76 \mathrm{ng} \cdot \mathrm{mL}^{-1}$ at $24 \mathrm{~h}$ and $17.5 \pm 0.95 \mathrm{ng} \cdot \mathrm{mL}^{-1}$ at 48 hours, and the amounts were $5.06 \pm 1.1 \mathrm{ng} \cdot \mathrm{mL}^{-1}$ at 24 hours and $13.3 \pm 1.05$ ng. $\mathrm{mL}^{-1}$ at 48 hours in HEK-293T cells. According to these data, the differences between the supernatant concentration of the R5-6/CWT and the R56C/CMUT were significantly obvious (Figure 2A, 2B). All data are summarized in Table 1.

PLA2G7 Gene Expression and PAF-AH Concentration The impact of $2486 \mathrm{G}$ on the expression of PLA2G7
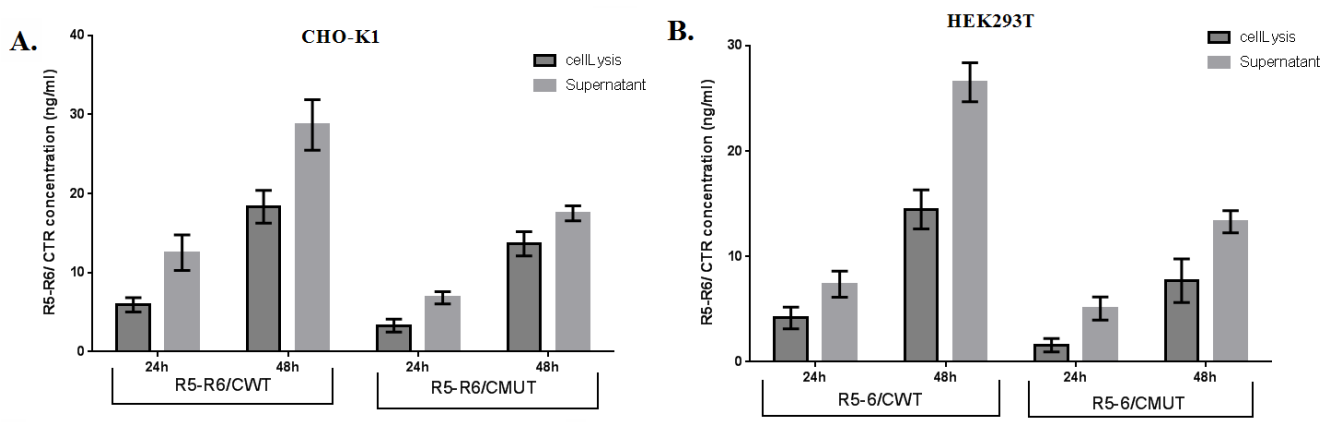

Figure 2. S2486G Mutation Influences on Reelin Secretion. A) Secretion of Reelin between Mutant and wild-type constructs in CHO-K1 cells. B) Reelin secretion of Mutant and wild-type constructs in HEK-293T cells $(n=3$, Mean \pm SD). 
Table 1. Levels of Reelin Protein Compared Between Supernatant and Cell Lysate from R5-R6 /CWT and R5-R6/CMUT Using the CHO-K1 and HEK-293T Cells Transfected by Appropriate Vectors after 24 and 48 Hours Follow-up $(n=3$, Mean \pm SD)

\begin{tabular}{|c|c|c|c|c|c|c|c|}
\hline \multirow[b]{2}{*}{ Cell type } & \multirow[b]{2}{*}{ Time (h) } & \multicolumn{2}{|c|}{ Supernatant } & \multirow[b]{2}{*}{ FC (WT/MUT) } & \multicolumn{2}{|c|}{ Cell-Lysis } & \multirow[b]{2}{*}{ FC (WT/MUT) } \\
\hline & & $\begin{array}{c}\text { R5-R6 /CWT } \\
\text { (ng mL-1) }\end{array}$ & $\begin{array}{l}\text { R5-R6/CMUT } \\
\text { (ng mL-1) }\end{array}$ & & $\begin{array}{c}\text { R5-R6/CWT } \\
(\text { ng mL-1) }\end{array}$ & $\begin{array}{l}\text { R5-R6/CMUT } \\
\text { (ng mL-1) }\end{array}$ & \\
\hline \multirow{2}{*}{ CHO-K1 } & 24 & $12.53 \pm 2.24$ & $6.83 \pm 0.76$ & 1.83 & $5.93 \pm 0.9$ & $3.3 \pm 0.81$ & 1.79 \\
\hline & 48 & $28.7 \pm 3.2$ & $17.5 \pm 0.95$ & 1.64 & $18.33 \pm 2.08$ & $13.6 \pm 1.52$ & 1.34 \\
\hline \multirow{2}{*}{ HEK-293T } & 24 & $7.36 \pm 1.2$ & $5.06 \pm 1.1$ & 1.45 & $4.16 \pm 1.04$ & $1.58 \pm 0.65$ & 2.63 \\
\hline & 48 & $26.53 \pm 1.6$ & $13.3 \pm 1.05$ & 1.99 & $14.4 \pm 1.8$ & $7.7 \pm 2.06$ & 1.87 \\
\hline
\end{tabular}

FC, fold change, WT/MUT, wild-type/mutant.

and the concentration of the encoded protein, PAF$\mathrm{AH}$, was assessed. Our data showed that the treatment of approximately $8 \times 10^{5} \mathrm{THP} 1$ cells with $\mathrm{R} 5-\mathrm{R} 6 / \mathrm{CWT}$ conditioned medium including $20 \mathrm{ng} / \mathrm{mL}$ for $3 \mathrm{~h}$ increased the PLA2G7 gene expression (fold change: 2.53) (Figure $3 \mathrm{~A}$ and $3 \mathrm{~B})$. A similar treatment, except for 16 hours, increased the PAF-AH level to 2.56 fold in comparison with base cells. By treating THP1 cells with R5-R6/CMUT conditioned medium, on the other hand, these levels diminished lower than THP1 base levels of PLA2G7 and PAF-AH. These findings suggested that S2486G mutation caused a reduction in the promotion of the PLA2G7 gene and therefore, led to a reduction in the PLA2G7 mRNA level lower than the level of THP1 cells. In sum, results demonstrated that S2486G can be implied as a 'Gain of Function' mutation through an unknown pathway. For a detailed comparison, refer to Table 2 .

\section{Discussion}

AS is a chronic inflammatory disease in which bone formation and cartilage degeneration are influenced by various mediators. Indeed, the etiopathogenesis of this disease, which is a prototype spondyloarthropathy, has not yet been deciphered. In this study, we aimed to investigate the possible disruptive effects of RELN S2486G mutation which warrant AS etiology through inflammatory mediators and PAF-AH.

To begin with, we showed that the S2486G mutation in the $6^{\text {th }}$ EGF-like domain of reelin reduces the secretion of reelin in both CHO-K1 and HEK-293T cell lines. As shown in Figures 2A and 2B, the whole level of reelin in both conditioned medium and cell lysate were less than the whole levels of wild-type reelin. Since the cloned fragments were expressed under the regulation of a quite strong promoter (cytomegalovirus promoter), the observed differences are probably due to the translational or post-translational modifications. I-Mutant2.0 predicted that the stability of the folded reelin protein is reduced. Serine is a polar amino acid while glycine is non-polar ${ }^{42}$; thus, their substitution can affect the protein folding. The endoplasmic reticulum, as a quality control apparatus, has a major role in packaging and exporting the correctly folded proteins. ${ }^{43}$ One of these quality control mechanisms is O-glycosylation in EGF-like domains. It has been demonstrated that serine residues, which are located between the second and third cysteine of the EGF-like domain (like S2486), are the target site of O-glycosylation by protein O-fucosyltransferase (POFUT1) enzyme which adds O-fucose to this site and thereby leads to stabilizing, accelerating of protein folding and secretion. ${ }^{44}$ These data are predicted by GlycoEP. Therefore, the S2486G substitution can abolish this action and result in a misfolded protein which will be disrupted by the endoplasmic reticulum. However, we believe that this uncertainty will soon be removed by further studies.

Our data suggest that reelin can be involved in
A.

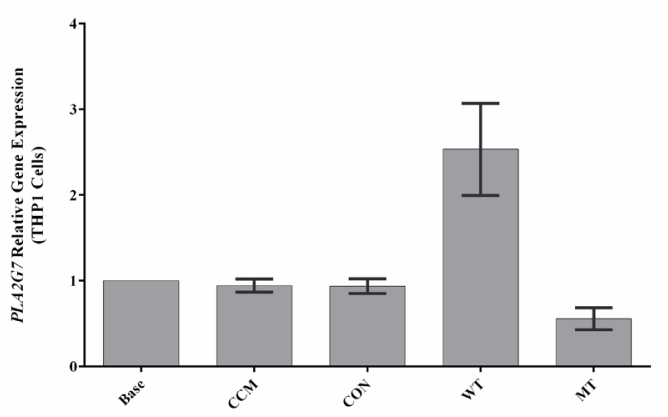

B.

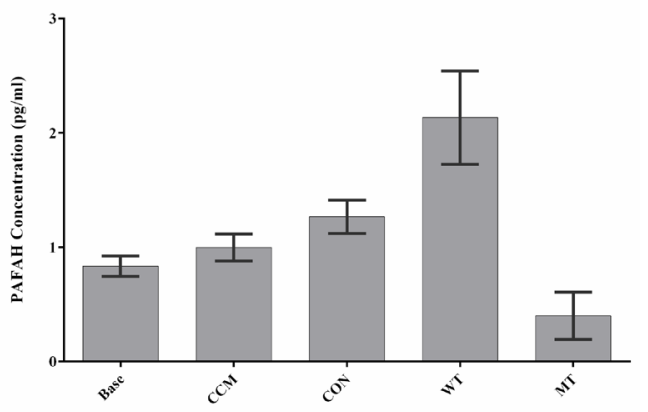

Figure 3. A) Relative gene expression of $P L A 2 G 7$ in THP1 cells $(P$ value $<0.001)$. B) The figure shows the concentration of PAF-AH in THP1 cells $(P$ value $<0.003)$. 
Table 2. Detailed Results from the Evaluation of the Concentration of PAF-AH and Gene Expression of PLA2G7 in THP1 Cells

\begin{tabular}{|c|c|c|c|c|c|c|}
\hline Aim & Method & Experiments & Mean $(n=3)$ & SD & FC Sample/Base & FC WT/MUT \\
\hline \multirow[t]{5}{*}{ PAF-AH concentration } & ELISA & THP1-base & 0.83 & 0.15 & 1 & * \\
\hline & & $\mathrm{THP} 1+\mathrm{CCM}$ & 0.99 & 0.20 & 1.19 & $*$ \\
\hline & & $\mathrm{THP} 1+\mathrm{CON}$ & 1.2 & 0.25 & 1.44 & * \\
\hline & & THP1+WT & 2.13 & 0.70 & 2.56 & ND \\
\hline & & THP1+MT & 0.4 & 0.36 & 0.48 & * \\
\hline \multirow[t]{5}{*}{ PLA2G7 gene expression } & RT-qPCR & THP1-base & 1 & 0 & 1 & * \\
\hline & & $\mathrm{THP} 1+\mathrm{CCM}$ & 0.94 & 0.13 & 0.13 & * \\
\hline & & THP1+CON & 0.93 & 0.14 & 0.93 & * \\
\hline & & THP1+WT & 2.53 & 0.9 & 2.53 & 4.6 \\
\hline & & $\mathrm{THP} 1+\mathrm{MT}$ & 0.55 & 0.2 & 0.55 & $*$ \\
\hline
\end{tabular}

ND, not-defined; ELISA, enzyme-linked immunosorbent assay.

*Significant.

inflammation. It has been shown that the reelin levels are increased in both serum and synovial fluid of RA patients and could be used as a diagnostic marker. ${ }^{45}$ Indeed, the liver is the main source of reelin in the blood. ${ }^{46}$ Despite the pathophysiology of RA, which is based on bone destruction through activation of osteoclasts, ${ }^{47}$ the main characterization of AS is cartilage erosion and formation of new bones in sacroiliac and facet joints mediated by osteoblast cells. ${ }^{48}$ The potential role of reelin protein in the development of cartilage has been illustrated ${ }^{49}$; the corticosterone hormone has a pivotal role in bone loss and leads to the elevation of reelin expression in the murine osteocyte cell line. ${ }^{50,51}$ Other complementary studies have revealed the association of several variants in the $R E L N$ gene with otosclerosis, a type of conductive hearing loss, following abnormal bone remodeling in the otic capsule of the ear. ${ }^{52}$

Additionally, it has been confirmed that reelin promotes Pla2g7 gene expression by stimulating macrophage VLDL receptors in mice. For the first time in humans, we detected the same pathway. PLA2G7 encodes PAF$\mathrm{AH}^{53}$ which belongs to the phospholipase A2 family. ${ }^{54}$ Inflammatory mediators have a pivotal role in triggering inflammation in AS. ${ }^{55,56}$ The PAF-AH protein hydrolyzes PAF, which is a potent pro-inflammatory agent and plays a staple role in inflammation, by releasing inflammatory eicosanoids and TNF- $\alpha$ from leukocytes and endothelial cells. Consequently, this process leads to more PAF releasing and causes increased platelet activation. ${ }^{57}$ PAF$\mathrm{AH}$ is generated largely by hepatocytes and macrophages; this protein is broadly scattered in human plasma, blood cells, and a variety of tissues. ${ }^{58}$ Besides, this enzyme reduces the inflammatory responses and this protein is a well-known biomarker for cardiovascular disease. ${ }^{59-61}$ In the in-vitro analysis, we showed that the S2486G caused the reduction of concentration and expression of PAF$\mathrm{AH}$ and PLA2G7, respectively. This can justify their roles in expanded inflammation which is associated with
AS pathophysiology. It has been illustrated that PAF$\mathrm{AH}$ can regulate epithelial-mesenchymal transition, as well. Therefore, it could control the initiation of bone regulation in preosteoblasts. ${ }^{62,63}$ Likewise, it has been elucidated that $\beta$-arrestin 2 can upregulate PLA2G7 and inhibits osteoclastogenesis in vitro which resulted in decreased bone resorption in vivo by regulating RANKL/ OPG production and ephrins mRNAs. ${ }^{64,65}$ Thus, PLA2G7 functions as a double-edged sword by playing a role in inflammation and osteogenesis, indirectly.

Herein, for the first time, we showed that S2486G is a pleiotropic mutation that reduced reelin secretion as well as decreased PLA2G7 gene expression. Even though by in-vitro analysis, we showed that S2486G results in reduced secretion of PAF-AH, other studies need to shed light on other molecular mechanisms, other networks, and important interactions of reelin in inflammatory pathways using appropriate animal models. In a nutshell, our data show the involvement of reelin in AS etiology through inflammation and also probably osteogenesis. We believe that the findings of this study hopefully broaden the horizons toward better understanding the molecular mechanisms contributing to AS. One inherent weakness of this study is that we should have evaluated the gene and protein expression using cartilage cell lines, in different stages, e.g. from chondrocytes to osteocytes, to show the involvement of reelin in chondrogenesis/osteogenesis pathways. We believe that future studies could fruitfully explore these issues.

In conclusion, this report points to the first association of the RELN gene with AS disease. The S2486G situated in the receptor binding site of reelin may alter the inflammatory or probably osteogenesis pathway for AS manifestations. However, further studies should be conducted to cast light on reelin roles in inflammation.

\section{Authors' Contribution}

MG, EEG: Conceptualization. EEG, ER and ARB: Methodology and data curation . EEG and ER: Software, writing the paper and 
original draft preparation. EEG, MG and ER: Validation. ER: Formal analysis and visualization. MG, MM: Investigation, resources and supervision. EEG, ER, ARB and MG: Writing, reviewing and editing the paper. MG, MM and ARJ: Project administration. MG: Funding acquisition.

\section{Conflict of Interest Disclosures}

The authors declare no conflict of interest.

\section{Ethical Statement}

The study protocol was approved by the local medical ethics committee of Tarbiat Modares University, Tehran, Iran. The study was performed during 2016-2018 at Tarbiat Modares University, Tehran, Iran.

\section{Acknowledgements}

We are especially grateful to the staff of Rheumatology Research Center (RRC) and the DeNA laboratory, Tehran, Iran, for helping us in this research. Additionally, we appreciate Dr. Azam Rahimpour, Shahid Beheshti University, Tehran, Iran, who gifted us the backbone plasmid, and Dr. Mehdi Banan, the University of Social Welfare and Rehabilitation Sciences, Tehran, Iran, for providing K562, and HEK293T cell lines. This research received no specific grant from any funding agency, commercial or not-for-profit sectors.

\section{Supplementary Materials}

Supplementary file 1 contains Table S1.

\section{References}

1. Imamura T, Saiki K, Okamoto K, Maeda J, Matsuo H, Wakebe $\mathrm{T}$, et al. Characterization of individuals with sacroiliac joint bridging in a skeletal population: analysis of degenerative changes in spinal vertebrae. Biomed Res Int. 2014;2014:879645. doi: 10.1155/2014/879645.

2. Schett G. Joint remodelling in inflammatory disease. Ann Rheum Dis. 2007;66(3):42-4. doi: 10.1136/ard.2007.078972.

3. Bruijnen T, Verweij J, van Duivenvoorden M, Bravenboer $N$, Baeten L, Denderen J, et al. Bone formation in ankylosing spondylitis during anti-tumour necrosis factor therapy imaged by $18 \mathrm{~F}$-fluoride positron emission tomography. Rheumatology. 2018;57(4):631-8. doi: 10.1093/rheumatology/kex448.

4. Maksymowych P, Chiowchanwisawakit P, Clare T, Pedersen J, Østergaard M, Lambert G. Inflammatory lesions of the spine on magnetic resonance imaging predict the development of new syndesmophytes in ankylosing spondylitis: evidence of a relationship between inflammation and new bone formation. Arthritis Rheum. 2009;60(1):93-102. doi: 10.1002/art.24132.

5. Garshasbi M, Mahmoudi M, Razmara E, Vojdanian M, Aslani S, Farhadi E, et al. Identification of RELN variant p.(Ser2486Gly) in an Iranian family with ankylosing spondylitis; the first association of RELN and AS. Eur J Hum Genet. 2020;28(6):754-62. doi: 10.1038/s41431-020-0573-4.

6. D'Arcangelo G. Reelin in the years: controlling neuronal migration and maturation in the mammalian brain. Adv in Neuroscience. 2014;12(1):597395-97. doi: $10.1155 / 2014 / 597395$.

7. Lambert de Rouvroit C, Goffinet AM. Brain Development in Normal and reeler Mice: the Phenotype. In: The Reeler Mouse as a Model of Brain Development. Springer, Berlin, Heidelberg. doi: 10.1007/978-3-642-72257-8_1.

8. Folsom TD, Fatemi $\mathrm{SH}$. The involvement of Reelin in neurodevelopmental disorders. Neuropharmacology. 2013;68:122-35. doi: 10.1016/j.neuropharm.2012.08.015.

9. Dazzo E, Fanciulli M, Serioli E, Minervini G, Pulitano P, Binelli $\mathrm{S}$, et al. Heterozygous reelin mutations cause autosomaldominant lateral temporal epilepsy. Am J Hum Genet. 2015;96(6):992-1000. doi: 10.1016/j.ajhg.2015.04.020.

10. Abdolmaleky HM, Cheng K, Russo A, Smith CL, Faraone SV, Wilcox $M$, et al. Hypermethylation of the reelin
(RELN) promoter in the brain of schizophrenic patients: a preliminary report. Am J Med Genet B Neuropsychiatr Genet. 2005;134(1):60-6. doi: 10.1002/ajmg.b.30140.

11. Fatemi S, Earle J, McMenomy T. Reduction in Reelin immunoreactivity in hippocampus of subjects with schizophrenia, bipolar disorder and major depression. Mol Psychiatry. 2000;5(6):654-71. doi: 10.1038/sj.mp.4000783.

12. Hornig T, Sturm L, Fiebich B, Van Elst LT. Increased bloodReelin-levels in first episode schizophrenia. PLoS One. 2015;10(8):e0134671. doi: 10.1371/journal.pone.0134671.

13. Smalheiser NR, Costa E, Guidotti A, Impagnatiello F, Auta J, Lacor $\mathrm{P}$, et al. Expression of reelin in adult mammalian blood, liver, pituitary pars intermedia, and adrenal chromaffin cells. Proc Natl Acad Sci USA. 2000;97(3):1281-6. doi: 10.1073/ pnas.97.3.1281.

14. Magnani A, Pattacini L, Boiardi L, Casali B and Salvarani C. Reelin levels are increased in synovial fluid of patients with rheumatoid arthritis. Clin Exp Rheumatol. 2010;28(4):546-548.

15. Ochiai-Shino H, Kato H, Sawada T, Onodera S, Saito A, Takato T, et al. A novel strategy for enrichment and isolation of osteoprogenitor cells from induced pluripotent stem cells based on surface marker combination. PLoS One. 2014;9(6):e99534. doi: 10.1371/journal.pone.0099534.

16. Appleton C, Pitelka V, Henry J, Beier F. Global analyses of gene expression in early experimental osteoarthritis. Arthritis Rheum. 2007;56(6):1854-68. doi: 10.1002/art.22711.

17. Taylor KE, Wong Q, Levine DM, McHugh C, Laurie C, Doheny $\mathrm{K}$, et al. Genome-wide association analysis reveals genetic heterogeneity of Sjögren's syndrome according to ancestry. Arthritis Rheumatol. 2017;69(6):1294-305. doi: 10.1002/ art.40040.

18. Du Y, Yang M, Wei W, Huynh HD, Herz J, Saghatelian A, Wan Y. Macrophage VLDL receptor promotes PAFAH secretion in mother's milk and suppresses systemic inflammation in nursing neonates. Nat Commun. 2012;3(1):1-8. doi: 10.1038/ ncomms2011.

19. McIntyre TM, Prescott SM, Stafforini DM. The emerging roles of PAF acetylhydrolase. J Lipid Res. 2009;50(1):255-9. doi: 10.1194/jIr.R800024-JLR200.

20. Boetkjaer A, Boedker M, Cui G, Zhao Y, Lukiw J. Synergism in the repression of COX-2-and TNFa-induction in platelet activating factor-stressed human neural cells. Neurosci Lett. 2007;426(1):59-63. doi: 10.1016/j.neulet.2007.08.050.

21. Kowanko IC, Bates EJ, Ferrante A. Platelet-activating factor inhibits proteoglycan synthesis and enhances neutrophilmediated proteoglycan degradation in cartilage explants. Arthritis Rheum. 1992;35(8):918-25. doi: 10.1002/ art.1780350811.

22. Fatemi SH. Reelin Glycoprotein: Structure, Biology and Roles in Health and Disease. Mol Psychiatry. 2005;10(3):251-7. doi: 10.1038/sj.mp.4001613.

23. Stacey M, Lin H-H, Hilyard KL, Gordon S, McKnight AJ. Human epidermal growth factor (EGF) module-containing mucinlike hormone receptor 3 is a new member of the EGF-TM7 family that recognizes a ligand on human macrophages and activated neutrophils. J Biol Chem. 2001;276(22):18863-70. doi: 10.1074/jbc.M101147200.

24. Kansas GS, Saunders KB, Ley K, Zakrzewicz A, Gibson RM, Furie $\mathrm{BC}$, et al. A role for the epidermal growth factor-like domain of P-selectin in ligand recognition and cell adhesion. J Cell Biol. 1994;124(4):609-8. doi: 10.1083/jcb.124.4.609.

25. StenfloJ, Ohlin A, Owen W, Schneider W. beta-Hydroxyaspartic acid or beta-hydroxyasparagine in bovine low density lipoprotein receptor and in bovine thrombomodulin. J Biol Chem. 1988;263(1):21-4.

26. He X, Semenov M, Tamai K, Zeng X. LDL receptor-related proteins 5 and 6 in $W n t / \beta$-catenin signaling: arrows point 
the way. Development. 2004;131(8):1663-77. doi: 10.1242/ dev.01117.

27. Schrijver I, Liu W, Brenn T, Furthmayr H, Francke U. Cysteine substitutions in epidermal growth factor-like domains of fibrillin-1: distinct effects on biochemical and clinical phenotypes. Am J Hum Genet. 1999;65(4):1007-20. doi: 10.1086/302582.

28. Duit S. Regulation and differential functions of ApoER2 and VLDL receptor in Reelin signaling. I Biol Chem. 2010;285(7):4896-908. doi: 10.1074/jbc.M109.025973.

29. Okoro EU, Zhang H, Guo Z, Yang F, Smith C, Yang H. A subregion of reelin suppresses lipoprotein-induced cholesterol accumulation in macrophages. PLoS One. 2015;10(8):e0136895. doi: 10.1371/journal.pone.0136895.

30. Nakano Y, Kohno T, Hibi T, Kohno S, Baba A, Mikoshiba K, et al. The extremely conserved C-terminal region of Reelin is not necessary for secretion but is required for efficient activation of downstream signaling. J Biol Chem. 2007;282(28):20544-52 . doi: 10.1074/jbc.M702300200.

31. Gattiker A, Gasteiger E, Bairoch AM. ScanProsite: a reference implementation of a PROSITE scanning tool. Appl Bioinformatics. 2002;1(2):107-8.

32. Thompson JD, Gibson TJ, Higgins DG. Multiple sequence alignment using ClustalW and ClustalX. Curr Protoc Bioinformatics. 2003;(1):231-2. doi: 10.1002/0471250953. bi0203s00.

33. DeLano WL. Pymol: An open-source molecular graphics tool. CCP4 Newsletter on Protein Crystallography. 2002;40(1):8292.

34. Capriotti E, Fariselli P, Casadio R. I-Mutant2. 0: predicting stability changes upon mutation from the protein sequence or structure. Nucleic Acids Res. 2005;33(2):306-10. doi: 10.1093/nar/gki375.

35. Kelley LA, Mezulis S, Yates CM, Wass MN, Sternberg MJ. The Phyre2 web portal for protein modeling, prediction and analysis. Nat Protoc. 2015;10(6):845-58. doi: 10.1038/ nprot.2015.053.

36. Boutet E, Lieberherr D, Tognolli M, Schneider M, Bairoch A. UniProtKB/Swiss-Prot. Methods Mol Biol. 2007;406:89-112. doi: 10.1007/978-1-59745-535-0_4.

37. Wang W, Xia M, Chen J, Deng F, Yuan R, Zhang X, et al. Data set for phylogenetic tree and RAMPAGE Ramachandran plot analysis of SODs in Gossypium raimondii and G. arboreum. Data Brief. 2016;9:345-8. doi: 10.1016/j.dib.2016.05.025.

38. Rozen S, Skaletsky H. Primer3 on the WWW for general users and for biologist programmers. Methods Mol Biol. 2000;132:365-86. doi: 10.1385/1-59259-192-2:365.

39. Livak KJ, Schmittgen TD. Analysis of relative gene expression data using real-time quantitative PCR and the 2(-Delta Delta C(T)) Method. Methods. 2001;25(4):402-8. doi: 10.1006/ meth.2001.1262.

40. Chauhan JS, Rao A, Raghava GP. In silico platform for prediction of $\mathrm{N}$-, $\mathrm{O}$ - and $\mathrm{C}$-glycosites in eukaryotic protein sequences. PLoS One. 2013;8(6):e67008. doi: 10.1371/ journal.pone.0067008.

41. Lammert DB, Middleton FA, Pan J, Olson EC, Howell BW. The de novo autism spectrum disorder RELN R2290C mutation reduces Reelin secretion and increases protein disulfide isomerase expression. J Neurochem. 2017;142(1):89-102. doi: $10.1111 /$ jnc. 14045 .

42. Watford M, Wu G. Protein. Adv Nutr. 2018;9(5):651-3. doi: 10.1093/advances/nmy027.

43. Guerriero CJ, Brodsky JL. The delicate balance between secreted protein folding and endoplasmic reticulumassociated degradation in human physiology. Physiol Rev. 2012;92(2):537-76. doi: 10.1152/physrev.00027.2011.

44. Takeuchi $\mathrm{H}, \mathrm{Yu} \mathrm{H}$, Hao $\mathrm{H}$, Takeuchi $\mathrm{M}$, Ito A, Li H, et al.
O-Glycosylation modulates the stability of epidermal growth factor-like repeats and thereby regulates Notch trafficking. J Biol Chem. 2017;292(38):15964-73. doi: 10.1074/jbc. M117.800102.

45. Magnani A, Pattacini L, Boiardi L, Casali B, Salvarani C. Reelin levels are increased in synovial fluid of patients with rheumatoid arthritis. Clin Exp Rheumatol. 2010;28(4):546-8.

46. Lotersztajn S, Julien B, Teixeira-Clerc F, Grenard P, Mallat A. Hepatic fibrosis: molecular mechanisms and drug targets. Annu Rev Pharmacol Toxicol. 2005;45:605-28. doi: 10.1146/ annurev.pharmtox.45.120403.095906.

47. Furst DE, Emery P. Rheumatoid arthritis pathophysiology: update on emerging cytokine and cytokine-associated cell targets. Rheumatology. 2014;53(9):1560-9. doi: 10.1093/ rheumatology/ket414.

48. Zhang X, Aubin JE, Inman RD. Molecular and cellular biology of new bone formation: insights into the ankylosis of ankylosing spondylitis. Curr Opin Rheumatol. 2003;15(4):387-93. doi: 10.1097/00002281-200307000-00004.

49. Diaz-Mendoza MJ, Lorda-Diez Cl, Montero JA, Garcia-Porrero JA, Hurle JM. Reelin/DAB-1 signaling in the embryonic limb regulates the chondrogenic differentiation of digit mesodermal progenitors. J Cell Physiol. 2014;229(10):1397-404. doi: 10.1002/jcp.24576.

50. Djordjevic J, Cvijic G, Davidovic V. Different activation of ACTH and corticosterone release in response to various stressors in rats. Physiol Res. 2003;52(1):67-72.

51. Ma Y, Wu X, Li X, Fu J, Shen J, Li X, et al. Corticosterone regulates the expression of neuropeptide $Y$ and reelin in MLO-Y4 cells. Mol Cells. 2012;33(6):611-6. doi: 10.1007/ s10059-012-0053-y.

52. Schrauwen I, Ealy M, Huentelman MJ, Thys M, Homer N, Vanderstraeten $\mathrm{K}$, et al. A genome-wide analysis identifies genetic variants in the RELN gene associated with otosclerosis. Am J Hum Genet. 2009;84(3):328-38. doi: 10.1016/j. ajhg.2009.01.023.

53. Du Y, Yang M, Wei W, Huynh H D, Herz J, Saghatelian A, et al. Macrophage VLDL receptor promotes PAFAH secretion in mother's milk and suppresses systemic inflammation in nursing neonates. Nat Commun. 2012;3:1008-10. doi: 10.1038/ncomms2011.

54. Law M, Cotton R, Berger G. The role of phospholipases A2 in schizophrenia. Mol Psychiatry. 2006;11(6):547-56. doi: 10.1038/sj.mp.4001819.

55. Stafforini DM. Biology of platelet-activating factor acetylhydrolase (PAF-AH, lipoprotein associated phospholipase A2). Cardiovasc. Drugs Ther. 2009;23(1):7383. doi: 10.1007/s10557-008-6133-8.

56. Sabzevary-Ghahfarokhi $M$, Shohan $M$, Shirzad $H$, Rahimian G, Bagheri N, Soltani A, et al. The expression analysis of Fra1 gene and IL-11 protein in Iranian patients with ulcerative colitis. BMC Immunol. 2018;19(1):17. doi: 10.1186/s12865018-0257-9.

57. Ramakrishnan $\mathrm{P}, \mathrm{Kumar} \mathrm{AV}$, Varghese $\mathrm{TP}$, Vanapalli $\mathrm{S}$, Nair K, Mingate MD. Platelet activating factor: A potential biomarker in acute coronary syndrome? Cardiovasc Ther. 2017;35(1):64-70. doi: 10.1111/1755-5922.12233.

58. Anderson BO, Bensard DD, Harken AH. The role of platelet activating factor and its antagonists in shock, sepsis and multiple organ failure. Surg Gynecol Obstet. 1991;172(5):415-24.

59. Abuzeid A, Hawe E, Humphries S, Talmud PJ. Association between the Ala379Val variant of the lipoprotein associated phospholipase A2 and risk of myocardial infarction in the north and south of Europe. Atherosclerosis. 2003;168(2):283-8. doi: 10.1016/s0021-9150(03)00086-8.

60. Kim M, Yoo HJ, Jang HY, Lee SH, Lee JH. Effects of overweight and the PLA2G7 V279F polymorphism on the 
association of age with systolic blood pressure. PLoS One. 2017;12(3):e0173611. doi: 10.1371/journal.pone.0173611.

61. Chen J, Yang L, Foulks JM, Weyrich AS, Marathe GK, McIntyre TM. Intracellular PAF catabolism by PAF acetylhydrolase counteracts continual PAF synthesis. J Lipid Res. 2007;48(11):2365-76. doi: 10.1194/jlr.M700325-JLR200.

62. Lehtinen L, Vainio $P$, Wikman $H$, Huhtala $H$, Mueller $V$, Kallioniemi A, et al. PLA2G7 associates with hormone receptor negativity in clinical breast cancer samples and regulates epithelial-mesenchymal transition in cultured breast cancer cells. J Pathol Clin Res. 2017;3(2):123-38. doi: 10.1002/cjp2.69.
63. Dunlop L, Hall BK. Relationships between cellular condensation, preosteoblast formation and epithelialmesenchymal interactions in initiation of osteogenesis. Int J Dev Biol. 1995;39(2):357-71.

64. Pierroz DD, Rufo A, Bianchi EN, Glatt V, Capulli M, Rucci $\mathrm{N}$, et al. Beta-Arrestin2 regulates RANKL and ephrins gene expression in response to bone remodeling in mice. J Bone Miner Res. 2009;24(5):775-84. doi: 10.1359/jbmr.081237.

65. Bianchi E, Ferrari SL. $\beta$-arrestin2 regulates parathyroid hormone effects on a p38 MAPK and NFKB gene expression network in osteoblasts. Bone. 2009;45(4):716-5. doi: 10.1016/j.bone.2009.06.020.

(c) () () 2020 The Author(s). This is an open-access article distributed under the terms of the Creative Commons Attribution License (http://creativecommons. org/licenses/by/4.0), which permits unrestricted use, distribution, and reproduction in any medium, provided the original work is properly cited. 